\title{
The Effects of Collective Leadership on Student Achievement and Teacher Instruction
}

\author{
Maryam Awadh \\ Edgewood College, United States of America, Madison, WI, USA \\ Email: mawadh@edgewood.edu
}

How to cite this paper: Awadh, M. (2018). The Effects of Collective Leadership on Student Achievement and Teacher Instruction. Open Journal of Leadership, 7, 250-264. https://doi.org/10.4236/ojl.2018.74015

Received: August 28, 2018

Accepted: December 22, 2018

Published: December 25, 2018

Copyright (C) 2018 by author and Scientific Research Publishing Inc. This work is licensed under the Creative Commons Attribution International License (CC BY 4.0).

http://creativecommons.org/licenses/by/4.0/

\begin{abstract}
In the past, the leadership position primarily involved how leaders handled their role. The notion of collective leadership is significant for constructing the educational community and sustaining inclusive collective participation. This paper shows the framework of the leadership, and comprehensively addresses the ways in which leaders have a direct impact on classroom instruction and student learning outcomes. The study outlines how leadership abilities are linked to student achievement and illustrates how principals and instructional leaders are the central figures of this leadership. The study found the ways in which leaders indirectly influence student achievement through their impact on teacher motivation and work conditions, and whether teachers' knowledge and skills have an effect on student achievement in the educational system. The influences of collective leadership on classroom instruction were examined, including ways in which changes in instruction could influence both teachers and students.
\end{abstract}

\section{Keywords}

Collective Leadership, Classroom Instruction, Learning Outcomes, Student Achievement

\section{Introduction}

In the past, the leadership position primarily involved how leaders handled their role. "A person in any position of authority was largely assumed to hold a leadership role" (Hernez-Broome \& Hughes, 2004: p. 26). Here, the authors state that a person who can handle a role of authority is fully appropriate for a leadership position. A leadership position today not only involves authority but is also based on cooperation within a team guided by the leader and on connecting with the group in order to encourage development and progress. With this type 
of collective, or shared, leadership, efforts are shared to achieve a common goal.

\section{Research Questions}

This study seeks to investigate the following research questions: How significant is the impact of collective leadership on our society? How does it manifest in the setting of an educational institution? Does it directly influence the skills of the teachers and the extent of student achievement? Is it impossible to successfully establish an organization or a school without considering the leadership position?

\section{The Purpose of This Study}

This study sought to analyze the concept of collective leadership and outline some of the central functions performed by the role, as well as thoroughly illustrate the impact on individual participation and performance within the collective leadership approach. The main elements of collective leadership are explained, which include: understanding the community, building a powerful team, promoting the individual, and creating change. This study addressed the ways in which these elements reflect on the members of the collective leadership, and the extent of the impact of leadership on the mission plan and member goals. The information gleaned from this study answered whether collective leadership has a stronger impact on student accomplishment than individual leadership. Additionally, this study addressed the ways in which the leaders indirectly influenced student achievement through their impact on teacher motivation and work conditions, and whether the teachers' knowledge and skills resulted in lower student achievement in the educational system. Finally, the influence of collective leadership on classroom instruction was examined, including the ways in which changes in instruction can influence both teachers and students.

\section{The Form of Collective Leadership}

Collective leadership is a dynamic way to focus on the views of society rather than the individual to accomplish collective goals. Collective leadership, sharing leadership, or co-leadership requires each member to expand the notion of leadership from a personal perspective to a cooperative one.

For example, collective leadership can take many forms in a school setting, including parent teacher organizations (PTO), instructional development meetings, etc. Because the school principal's leadership ability has significant influence on the academic achievement of the students, the principals are responsible and accountable for the ability of each staff member to clarify the rules and regulations for the community.

While leaders are the key to success in the education system, collective leadership is a challenging activity. It requires wisdom and passion, as well as ongoing commitment. The community must believe in the abilities and skills of the 
leader which will assist the leader in developing and contributing to the evolution of the institution. Whereas collective leadership must manage the school and prepare for unexpected circumstances, the leaders must also keep the teachers and school community informed of new systems and policies. Collective leadership must be dependable, explicit, and collaborative with the staff in order to engage them in the educational and social system. These leaders are responsible for ensuring that each staff member is able to clarify the rules and regulations for his or her community, and they have a direct and indirect effect on the motivation and inspiration of classroom instruction and student learning. Collective leadership must provide the right environment for teamwork, facilitate the participation of all members, and provide the organization or school with a variety of opinions.

\section{The Conceptual Framework of the Collective Leadership}

Collective leadership creates opportunities for participation and encourages sharing among different groups of people, allowing them to work together to create new ideas for the educational system. The concept of collective leadership is fundamental for building the educational community and constructing collective participation. According to Maenette Benham at the University of Hawaii School of Hawaiian Knowledge, collective leadership is "the result of a dynamic process that brings together a diverse community of people around a set of pressing issues in an effort to build broad-based knowledge and participation that leads to constructive change" (Militello \& Benham, 2010: p. 622). It is clear that collective leadership describes a group of people working together for a shared mission in order to achieve success, whether this involves radicalorsuperficial changes in the field of education or in the community. It is this collective action between the leader and the participant group that is used to gather differing opinions, discuss any alternatives, weigh the options, and, finally, reach a prudent and rationalagreement that is effective for the individual or community. These decisions often impact students and teachers alike. The duty of collective leadership is to share the decision-making process with a team to expose thoughts and opinions regardless of race, color, religion, or socioeconomic status. The members of the collective leadership team share the common aim of improving the community; they can offer diverse perspectives on such issues because of their backgrounds. From this perspective, collective leadership requires each member to expand the notion of leadership from a personal perspective to a cooperative environment. A collective leadership team can more easily understand the needs of all parts of the community due to the different opinions of members on each case or issue that requires attention. Collective leadership is an important duty within the community because it distributes the task of decision-making and determining a solution among members, regardless of their leadership power or social position.

Collective leadership is a co-leadership approach that encompasses a rela- 
tionship or procedure regardless of individual capacity or personal background of the members. "Unlike individual heroic leadership, co-leadership embraces the diversity of people and perspectives, and frees up self-initiative and collective intelligence" (Gauthier, 2004: p. 2). Here, the author explains that collective leadership is quite different from individual leadership. Collective leadership, or co-leadership, accepts and promotes the diversity of the community and its differing viewpoints to enable a collective intelligence and self-initiative.

\section{The Approach of Individual Participation during Collective Leadership}

Collective leadership requires the contributions of each individual endeavoring to discuss the purpose of change, take the necessary steps for change, and, finally, determine a suitable plan to implement change. This process for creating change is an effective way to learn the views of each member in order to exchange ideas and gain a deeper understanding of the given situation. Each individual must be fully responsible and accountable for the changes they approve of for their community; they must be active listeners and converse openly with others in order to determine the necessary steps for change. The team also creates an appropriate scheme that will be productive for each participant. "The exchange relationship between transactional leaders and their followers is based on an implied contract that involves positive reinforcement for a higher level of performance" (Jung \& Sosik, 2002: p. 315). The authors indicate that an exchange in tasks between leaders and members promotes positive interaction and increases the level of functional performance. Individual participation is based on mutual respect that aims to understand the perspectives of others. Each individual participant listens carefully to all members in order to provide feedback with impartiality, which will positively reflect the individual morals concerning the schools or organizations. The participation of individuals might encourage the exchange of views despite different cultural backgrounds, opinions, or skills, resulting in effective communication and teamwork that acts as an engine for community growth. At the end, the collective leadership would apply initial objectives and fundamental rules that promote individual participation effectively, and the rules agreed upon within the group will help enhance the ability of each individual to achieve common goals.

Collective leadership directs all participants toward a main issue, which should lead the group to make a unanimous decision in order to effectively create or modify the educational system or other positions. Kuenkel (2008) explains the importance of the leadership environment: "Leaders can create an atmosphere, a space, in which the appreciation of a person as a person is present" (p. 8). It is important for leaders to provide a space that allows each person in the group to feel secure in sharing his or her opinions and to exchange appreciation and respect. Hence, collective leadership can improve the affection and respect that is reflected in team behavior and motivation, such as listening to other 
perspectives, despite differing opinions. Collective leadership enhances the exchange of ideas through daily practice that leads the community to gain a better understanding of the cultures and beliefs of others. In my opinion, if the leaders did not allow school members to share differing thoughts, the team would feel unrelated to the decision and uninvolved in the community. According to $\mathrm{Ku}$ enkel (2008), "Leading never takes place in isolation; it is always a collective endeavor" (p. 1), because leaders do not act in a segregated environment; instead, leadership requires a cooperative effort. Hence, collective leadership indicates that group participation is part of the responsibility of effective leadership. An individual can define an issue by sharing his or her perspective even if there are conflicting opinions. The individual is then willing to implement changes if there are supporters or if there is unanimous agreement upon a solution. Boies and Howell (2006) and Hooper and Martin (2008) mention that a team with conflicting relationships could lead to unfavorable team outcomes such as team disagreement and decreased contentment.

Recently, many leaders have begun to converse with their community in order to better understand the community's needs. Leaders are involved in society as active participants in the school environment, and host various meetings or events in order to exchange opinions about issues in the community or school system. According to Edmonson (2011), "Investing the time and effort to personally connect with others makes everyone feel like a partner" (p. 104), illustrating that it is crucial for leaders to communicate with others in order for them to feel they are active participants on the team. For example, leaders can avoid a lack of effort and lack of focus in the community by building trust, respect, and a relationship with the school members for the purpose of providing a suitable cooperative environment.

For example, in Saudi Arabia, the leaders rarely cooperate or interact with the community because the basic requirements of their position only involve responsibility for tasks. They might become more involved if the issue is related to a school member, parent, or teacher within their community. However, the decision-making process is handled privately and involves only the necessary participants. This approach allows co-leaders to suggest changes and requires their opinions or actions to be approved by others without involving the community in making decisions. According to Drummond and Al-Anazi research (1997) which is focusing on the leadership style in the public and private school found the Saudi manager perceived himself as authoritative and had no desire to share their perception with the team or others.

\section{The Elements of Collective Leadership}

Collective leadership is a cooperative task that engages each member in developing the school environment from a common perspective. According to Santovec (2008), "Leadership is not an individual endeavor" (p. 3), meaning that leadership demands a collective effort. Collective leadership is dependent upon 
four elements that form the basis for producing results that will create a cooperative community with the will to make the required changes. These elements are understanding the community, building a powerful team, promoting the individual, and, finally, creating the change.

\subsection{Understanding the Community}

A thorough understanding of the demographics and concerns of the local society is an important factor in enhancing collective leadership. Building and encouraging positive social interaction among the members of the collective leadership team engenders a safe and appropriate environment for all involved. It is important for the leaders to understand the history of the community and its culture because leaders often deal with a variety of individual backgrounds and perspectives. They must know the history of the participants (cultural background, education, language and race, etc.) in order to better understand their main concerns, which will allow collective leadership to build faith among members. "Building relationships has to be built on a foundation of honesty and trust" (Anderson, 2012: p. 16). The author mentions that the social relationship must be based on integrity and confidence. Collective leadership must establish a positive relationship between staff and in the community because a lack of positive social relations would limit the team's ability to improve and contribute effectively to the community.

Additionally, collective leadership allows those involved to create diverse work environments that can lead to new avenues of change. Understanding the local culture expands the perceptions of leadership because the leader can use such understanding to make appropriate decisions for an educational environment that is a mixture of cultures, races, and backgrounds. In addition, each individual who participates in the collective leadership team would be familiar with this diversity and would encourage the team to respect and appreciate the multicultural environment.

The function of collective leadership must be fully understood by the participating members because the group members must communicate to help their community and improve their personal skills. Team members should feel invested in a common agenda. If team members feel unconnected, they will be ineffective in their tasks or duties. Leadership involves a willingness to fairly observe and evaluate the demographics of the community. The best way to do so is to demand the parents to fill out a form on the first day of school that provides information about the family background. This would allow leaders to form a better understanding and, thus, closer relationships with community members. For instance, some schools send a letter to the parents of students written in the students' native language. In my opinion, this is a huge step toward understanding different cultural backgrounds as well as enhancing each family's participation and sense of belonging to the school community. Schools also provide other methods of communication with families, such as PTOs, parties, and volunteer 
activities, which facilitate and encourage social interaction based on the individual or group needs despite their differences and diversity.

\subsection{Building a Powerful Team}

Collective leadership features elements that support all group members in building a powerful team. It is important that collective leadership encourages positive thinking and motivation among members and creates an achievable vision to build an effective team. All individuals involved in collective leadership share their opinions or concerns to jointly develop a new approach for a common purpose. Even if these opinions cause conflict or disagreement, team members need to remain open-minded with one another to feel acceptable of their peers' opinions. "Asking people what they need and listening to them is important as the group agrees on how they will work together" (Benham, Militello, \& Halladay, 2007: p. 12). The writers suggest that members must share their thoughts and listen, which are requirements for the successful cooperation of a group. Englart (2009) states that it is important to "[e] mpower all members in active listening and speaking" (p. 15). For example, interpersonal skills are a central feature of a good leader because they assist in building relationships among community members in order to understand the team. Leaders must exhibit solidarity and must avoid any cultural prejudice or bias that could be detrimental to the community and harmful to effective teamwork.

To build a powerful team, leaders must trust the team and their work and must express this trust. The purpose of demonstrating trust is to give the team confidence and make them feel empowered by encouraging and motivating them to do their best. The ability to build a powerful team is linked to a leader's communication skills. As long as leaders can create a confident environment among followers, they will increase their authority on the team. According to Harkins (2006), "Making teams hold to their commitments and keeping the team's view of its goals clear" (p. 4) is also a central role of a leader. The author states that teams need to be committed to clear goals in order to be part of the achievement.

\subsection{Promoting the Individual}

Promoting the individual is the third important element supporting collective leadership. While collective leadership is a powerful incentive for individual improvement, each individual is also committed to the shared goal of improving the community. Individuals participate by sharing their ideas, thoughts, and arguments, and they have the opportunity to express their opinion even if it is not considered "correct". Members of a collective leadership can help others with their group tasks, so they are able to change their perspective, learn new methods, and respect other opinions. Changing one's perspective is dependent upon the opinion of the group. Even if contrasting opinions arise, helping the team consider new methods for developing their organization remains the focus. 
The purpose of promoting the individual within collective leadership is to gain the benefits of diverse views regardless of whether they are for or against the personal views of all members.

For example, in schools, teachers might encourage their peers in order to learn new instructional methods from each other that will help them improve the academic lessons, even if the new methods are completely different from their own teaching perspectives or personal thoughts. Ross and Gray (2006) found that collective teacher efficacy influenced teachers' willingness to assist each other (p. 802). Teachers can enhance their methods by observing one another and can overcome pitfalls and difficulties in their own teaching by exchanging ideas with others on the development of methodology. I believe that teachers working collectively or as part of a collective leadership can effectively promote the individual while maintaining a position as a key member of an interdependent team. Nevertheless, conflict between individuals is the main destructive power in team environments.

Collective leadership needs to give the team members space to evolve and grow, and the leaders should promote the team effectively. The ability of the collective leadership involves efficiently performing within the team as well as within the community to implement strategies, resolve issues, acclimate to change, and encourage invention.

\subsection{Creating Change}

Creating change through a collective leadership group is a useful way to impact society. According to Nienow (2009), "We need leadership that will help our institutions serve the full community well" (p. 3). To create change in society, leadership could be promoted as a device for carrying out the needed alterations. This is not only a task for leaders but is also dependent upon all members of the community. Data and qualitative information must be collected in order for community values to be properly assessed and eventually changed. The members must decide which current conditions need to be immediately and radically altered. Competence motivates a leader's followers, and care is necessary in participating in the efforts for change with regard to what is beneficial for the community.

Collective leadership seeks to understand the concerns of the individual members of the leadership team, in order to motivate them to work, collect information, and address solutions. The team needs to work together actively while the leader clearly outlines the purpose of the work. "You need an ongoing evaluation process to support the leadership in attaining their goals as the plan continues to evolve" (Benham, Militello, \& Halladay, 2007: p. 46). The authors indicate that collective leadership must assess the process in order to continue and must encourage the team to achieve the objectives of improvement plans that result in critical changes. Collective leadership teams must ensure the plan is clear, with opportunities for all to be part of the initiative. 
Creativity within the group is the source of ideas for the collective leadership; it provides the energy to effect change. Leadership provides feedback and assessment to group members of the school, which urges them to proceed and to insist on creating changes, particularly in an educational setting. The most powerful jump in education is moving from a traditional classroom or traditional teaching to a new method such as: using computers inside the classroom and teaching a technology subject, for example, the computer lesson taught in the elementary grades. Collective leadership can tackle this issue by encouraging the leadership team to adopted new teaching and learning methods that are appropriate for all students and their future career.

\section{The Influences of Collective Leadership on the Education and Student}

Collective leadership shares contributions with school members, such as students, teachers, and parents, in order to improve the learning system and make changes to the curriculum, teaching methodology, or extra-curricular activities. According to Samuels (2010), "The traits of effective school principals have found that high student achievement is linked to 'collective leadership': the combined influence of educators, parents, and others on school decisions" (p. 1). The author implies that students achieve the highest levels of learning from the positive impact of leaders characterized by a collective approach. Collective leadership in the learning community influences students directly and is seen in teachers and parents as well as school rules. "Collective leadership starts where leaders realize the truth of the old adage, 'none of us is as smart as all of us', but it doesn't stop there" (Pór, 2008: p. 13). Participation in collective decision-making reflects the intelligence of the group, and this adage explains that collective decisions are wiser than an individual decision.

According to McGuffin (2011), "Strong leadership within a school often enhances the school's students' opportunities to succeed, both personally and academically" (p. 1). In other words, powerful leadership in a school environment increases the opportunity for students to achieve success on both the personal and the academic level. The new opportunity could be an increase in the students' ability to accomplish their academic goals, as well as raise their academic level by involving experienced teachers and providing a healthy and safe environment for students.

Collective leadership has a strong correlation to teachers' work setting, motivation, and the capacity which all those are related to students' achievement (Louis, Leithwood, \& Anderson, 2010). The result of Louis and his colleagues that collected from the survey and state websites found the cooperation among leaders could enhance teachers' abilities to achieve educational objectives and increase student accomplishment. Louis and his colleagues also indicated that the collective leadership has a more substantial impact than working individually. Because working as a group must always seek to improve and establish rules 
to keep the community rejuvenated. The leadership team places their trust and values in improving the school. For instance, aPTO is a well-known group that organizes meetings and is considered collective leadership because it allows members to be active participants in the development of the school environment. The school gives families the opportunity to contribute financially and morally. The PTO meetings provide the parents, teachers, and school with this opportunity by supporting this leadership team; in turn, the members make decisions that are reflected in school improvement and student achievement.

\subsection{The Influences of Collective Leadership on Teachers}

Pont, Nusche, and Hopkins (2008) indicated that the shared leadership does not lead to loss of the school leader's authority. Instead, collective leadership enhances the sharing perspective and does not infringe on the duties of individual leadership (p. 18). The division of roles among the collective leaders is not meant to reduce the number of tasks, but to distribute the work involved in carrying out the massive effort of improving the status of students' education. Collective leadership has a stronger effect on student performance and outcomes than individual leadership, as shown by Johnson, Uline, and Perez (2011): "Effective leaders work to develop a shared vision of the future, building consensus for relevant short-term goals" (p. 6). Dynamic leaders improve collective work and create a common vision by creating short- or long-term plans that can increase students' level of education and achievement. Part of leaders' influence is having a sense of awareness of themselves and others which is constantly growing because they are responsible for maintaining work environments that are compatible with the needs of all community members. "The influence of collective leadership on students operates through its influence on teacher motivation and work setting" (Louis, Leithwood, \& Anderson, 2010: p. 29). As the students learn through the teacher, they are indirectly influenced by collective leadership because the teacher is part of the collective decision-making process. According to Lee (2015) who collected data from individual principal and focus-group interviews found that collective leadership can impact teacher mission. In this case, the teachers can feel more empowered to share their vision and decision-making effectively (Lee, 2015). Through collective leadership, the teacher can provide a collaborative environment based on the exchange of experiences, professional development, and innovative teaching methods, all of which might be reflected in the students' academic performance. For instance, some school provides a professional development for teachers to improve the teaching skills that reflected on student progress. The professional development for the teachers can include mentoring, observation, team meeting, and workshop. According to Standards for Staff Development (2001) mentioned that Learning Forward Association "advocates that school districts dedicate at least $10 \%$ of their budgets to staff development and that at least $25 \%$ of an educator's work time be devoted to learning and collaboration with colleagues" (NSDC, 2001). 
Leaders have an impact on student achievement primarily through influencing the work setting and teachers' motivation and approach. Leaders do not directly impact teacher knowledge or skills, resulting in much of the concerns about student achievement in the education system. Recent research has found that "A vision of academic success for every student is set through collaboration and shared leadership" (Lee, 2015: p. 69). In this case, the collective leadership influences the emotions and faith of teachers that reflect on the students learning.

The teachers share tasks with the leaders, while the students contribute to these tasks because they engaged in a variety of classroom tasks and instructions. Leaders can help develop teacher abilities and skills by offering professional development courses or observational meetings, which results in students learning new methods from the teachers' experience. According to Leithwood and Louis (2004), "When we think of leaders in formal administrative roles, the greater the challenge the greater the impact of their actions on learning" (p. 5).

According to Rautiola's study (2009) "Much of the success of schools and teachers appears to depend on collective efficacy, alignment of goals and accommodating working conditions, which are conducive to student learning" ( $\mathrm{p}$. 29). This indicates that much of the success of schools and among teachers relies on collective efficacy, which helps them to adapt to working conditions and achieve goals that can raise the level of student academics. For example, collective leadership can improve the teachers' performance by involving them as contributors in surveys, observations, or meetings; this, in turn, can provide new opportunities to share their visions or experiences. The cooperation of teachers and leaders is the path to progress and success because it builds a sense of responsibility toward themselves and others.

\subsection{The Influences of Collective Leadership on Classroom Instruction}

Collective leadership has a strong impact on classroom instruction. According to Rautiola's research (2009) indicated that "Transformational leadership styles leading to instructional leadership have been shown to improve student achievement" (p. 28). The author mentions that transformative leadership guides instructional assistance to enhance student outcomes and achieve their goals. It can be argued that the ideal leadership style encourages all team members to exchange ideas, and that part of the leader's role is to display enthusiasm and positive energy, which are then reflected in team morale. In addition, collective leadership should encourage school members to be active participants who are motivated to work toward a common goal, such as student achievement or classroom instruction. Leithwood and Mascall (2008) state that this "[p] ersistently urges school leaders to be 'instructional leaders' and to take responsibility for improving the knowledge and skills of teachers", (p. 554); this suggests that school leaders can be instructional leaders who develop teacher skills. Participative leadership theory implies that leaders should encourage school members or 
team members to cooperate and contribute to the decision-making process, and that leaders should protect these rights. "Effective principals recognized that collaborative networks among educators were essential for successful teaching and learning" (Blasé, 2000: p. 135). This quote illustrates that some leaders consider establishing a collective network within a teacher climate as fundamental to aprosperous teaching and learning environment. For instance, teachers can exchange experiences by observing peer classroom instruction, participating in professional development, and sharing coursework or attending conferences; they can thus develop their skills and knowledge, allowing for both personal and professional growth. Moolenaar (2011) states that, "[b] y exchanging knowledge, sharing experiences, and collectively searching for solutions to problems, teachers may build confidence in their team's collective capability to motivate students, offer a targeted instructional program in support of student learning, and handle difficult situations" (p. 9). The author explains that the exchange of knowledge, shared experiences, and collective troubleshooting may help teachers to build confidence in their ability to motivate students, as well as to seek a targeted educational program to support students and deal with challenging cases. Sharing the responsibility serves each member by relieving some of the burden through teamwork and unleashes individual creativity.

\section{Suggestions and Strategies for the Future}

The traditional leadership role requires the ability to handle a position of authority; today, however, there are additional factors involved. The new duty of leadership is to change, innovate, and share, so that the mission of leadership is based on cooperation among members. Future research should examine the collective leadership principals within the school level by doing extensive studies that show the effectiveness of the collective leadership on students learning and school outcomes. Some research should include each member as a part of future study regardless of their differences or level. The studies should be focused on student achievement, and how the collective leadership would be part of the school extracurricular interests and school activities.

It is recommended that further studies implement the effectiveness of the relationship between the collective leadership and school outcomes. For example, the most recent study by Ni, Yan, and Pounder (2017) found that "principals perceived themselves to have the greatest influence in school decisions in almost all key decision areas". This study can encourage researchers to examine the relationship between the collective leadership and teachers and how this relationship could impact the school performance. Future research could also create network connections among the leaders from different schools and among the team members so they may assess their work periodically and expeditiously to evaluate which approaches impact positively on their performance or school outcomes. 


\section{Conclusion}

This literature indicated that collective leadership is an essential tool for building and developing society because it relies on a common mission. This mission should be pursued as a collective task, not just an individual one, in order to produce more effective results. The task of collective leadership is to assist all society members in building power and amplifying the common vision, value, or mission. It also inspires individuals to learn about other cultures, races, ethnicities, and values, because this diversity is the foundation for building collective leadership with active members.

In an educational setting, this study indicated that collective leadership can also have a strong influence on students' academic performance, teachers' abilities, and the effectiveness of classroom instruction. This literature mentioned that collective leadership is based on several elements that can influence the success of leadership, such as understanding the community, building a powerful team, promoting the individual, and creating change. Each of these elements impacts the team and creates a cooperative society with the desire to make the necessary changes. Furthermore, collective leadership enhances teachers' skills, provides a collaborative environment based on the exchange of experiences, and can positively affect student achievement. Collective leadership helps school members be actively linked to a common purpose that impacts instruction and student performance. Overall, this study concluded that the collective leadership mission is leading the team to share views on society, determine the appropriate views, and act on them.

\section{Conflicts of Interest}

The author declares no conflicts of interest regarding the publication of this paper.

\section{References}

Anderson, D. (2012). Is Building Relationships the Key to Leadership? Performance Improvement, 51, 15-22.

Benham, Militello, \& Halladay (2007). The Collective Leadership Framework. Battle Creek, Michigan: W.K. Kellogg Foundation.

Blasé, J. (2000). Effective Instructional Leadership: Teachers' Perspectives on How Principals Promote Teaching and Learning in Schools. Journal of Educational Administration, 38, 130-141.

Boies, K., \& Howell, J. (2006). Leader-Member Exchange in Teams: An Examination of the Interaction between Relationship Differentiation and Mean LMX in Explaining Team-Level Outcomes. The Leadership Quarterly, 17, 246-257. https://doi.org/10.1016/j.leaqua.2006.02.004

Drummond, H., \& Al-Anazi, F. B. (1997). Leadership Styles in Saudi-Arabia: Public and Private Sector Organisations Compared. Cross Cultural Management: An International Journal, 4, 3-8. https://doi.org/10.1108/eb008425

Edmonson, R. (2011). Multiple Leadership Intelligence: Powerful "Whole Brain” Solu- 
tions to Persuade, Make Decisions, Inspire, Transform Thinking (p. 104). Hong Kong: Paradigm 21 Group. http://books.google.com/books?id=8_tAywAACAAJ

Englart, J. (2009). Collective Organisation. 1-20. https://organizingforpower.files.wordpress.com/2009/06/working-in-collective-organiz ations.pdf

Gauthier, A. (2004). Developing Collective Leadership: Partnering in Multi-Stakeholder Contexts (Included in Part IV of the Book) (pp. 1-20).

Harkins, P. (2006). 10 Leadership Techniques for Building High-Performing Team (p. 6).

Hernez-Broome, G., \& Hughes, R. L. (2004). Leadership Development: Past, Present, and Future. Human Resource Planning Society, 24-32. http://www.highbeam.com/doc/1P3-629467231.html

Hooper, D., \& Martin, R. (2008). Beyond Personal Leader-Member Exchange (LMX) quality: The Effects of Perceived LMX Variability on Employee Reactions. The Leadership Quarterly, 19, 20-30. https://doi.org/10.1016/j.leaqua.2007.12.002

Johnson, J. F., Uline, C. L., \& Perez, L. G. (2011). Expert Noticing and Principals of High-Performing Urban Schools (pp. 1-33). San Diego, CA: ERIC Database.

Jung, D. I., \& Sosik, J. J. (2002). Transformational Leadership in Work Groups: The Role of Empowerment, Cohesiveness, and Collective-Efficacy on Perceived Group Performance. Small Group Research, 33, 313-336.

https://doi.org/10.1177/10496402033003002

Kuenkel, P. (2008). Leadership-A Pathway to Collective Intelligence (p. 9).

Lee, K. (2015) The Influence of Collective Instructional Leadership on Teacher Efficacy. Theses and Dissertations, Educational Leadership Studies, 12.

https://uknowledge.uky.edu/edl_etds/12

Leithwood, K., \& Louis, K. S. (2004). Review of Research: How Leadership Influences Student Learning (p. 90). Center for Applied Research and Educational Improvement, Ontario Institute for Studies in Education. http://conservancy.umn.edu/handle/11299/2035

Leithwood, K., \& Mascall, B. (2008). Collective Leadership Effects on Student Achievement. Educational Administration Quarterly, 44, 529-561.

https://doi.org/10.1177/0013161X08321221

Louis, K. S., Leithwood, K., \& Anderson, S. E. (2010). Investigating the Links to Improved Student Learning (p. 338). New York: The Wallace Foundation. http://www.wallacefoundation.org

McGuffin, S. R. (2011). Exploring the Direct and Indirect Effects of School Leadership on Student Achievement in Kentucky High Schools (p. 10).

Militello, M., \& Benham, M. K. P. (2010). “Sorting Out” Collective Leadership: How Q-Methodology Can Be Used to Evaluate Leadership Development. The Leadership Quarterly, 21, 620-632. https://doi.org/10.1016/j.leaqua.2010.06.005

Moolenaar, N. (2011). Linking Collaboration Networks, Collective Efficacy, and Student Achievement. Linking Networks and Achievement, 31, 1-44.

National Sta Development Council NSDC (2001). NSDC's Standards for Staff Development. Oxford, $\mathrm{OH}$.

Ni, Y., Yan, R., \& Pounder, D. (2017). Collective Leadership: Principals' Decision Influence and the Supportive or Inhibiting Decision Influence of Other Stakeholders. Educational Administration Quarterly, 54, 216-248.

Nienow, D. (2009). Why Collective Leadership Matters (pp. 1-9). 
Pont, B., Nusche, D., \& Hopkins, D. (2008). Improving School Leadership (Vol. 2: Case Studies on System Leadership). Paris: Organisation for Economic Cooperation and Development.

Pór, G. (2008). Collective Intelligence and Collective Leadership: Twin Paths to Beyond Chaos. Amsterdam: University of Amsterdam. https://aisel.aisnet.org/sprouts_all/207/

Rautiola, J. D. (2009). Effects of Leadership Styles and Student Academic Achievement. Marquette, MI: School Leadership and Academic Achievement, Northern Michigan University.

https://www.nmu.edu/sites/DrupalEducation/files/UserFiles/Files/Pre-Drupal/SiteSecti ons/Students/GradPapers/Projects/Rautiola_James_MP.pdf

Ross, J. A., \& Gray, P. (2006). School Leadership and Student Achievement: The Mediating Effects of Teacher Beliefs. Canadian Journal of Education, 29, 798. https://doi.org/10.2307/20054196

Samuels, C. A. (2010). School Principals; School Administration; Educational Leadership; Decision Making. Education Week, 29, 4.

Santovec, M. L. (2008). Report Information from ProQuest. Women Leaders: Collective and Compassionate, 17, 1-7. 